\title{
Guidelines for assessing the knowledge management maturity of organizations
}

\author{
C.J. Kruger \\ Department of Informatics \\ University of Pretoria \\ Pretoria \\ neels.kruger@postino.up.ac.za
}

\author{
M.M.M. Snyman \\ Department of Information Science \\ University of Pretoria \\ Pretoria \\ rsnyman@lantic.net
}

In a recent article Kruger and Snyman hypothesized that progressions in knowledge management maturity (from a strategic perspective) are directly related to an increased ability to speed up the strategic cycle of imitation, consolidation and innovation. The arguments proposed, however, neglected to supply the reader with a practical toolkit or even a roadmap (a time-related matrix, or questionnaire) to successfully measure succession in knowledge management maturity. This article builds on the previous one and proposes a questionnaire consisting of six sections, containing 101 descriptive questions, to enable organizations to test and assess their knowledge management maturity empirically. The development of an instrument to measure knowledge management maturity required adhering to a research design that combined theoretical propositions with practical experimentation. As a point of departure, a knowledge management maturity matrix consisting of seven maturity levels was formulated. All questions contained within the matrix were benchmarked against a survey questionnaire developed by the public management service of the OECD (PUMA) and were also pre-tested and validated. This process of refinement led to the formulation of the Knowledge Management Maturity Questionnaire. To avoid any taint of this research being based only on theoretical propositions, the questionnaire was tested by 178 master students of the University of Pretoria, South Africa, in nine different industries. The proposed questionnaire provides a bridge between theoretical propositions and practical usability, not only enabling knowledge management practitioners to assess the level of knowledge management maturity reached successfully but, more importantly, also serving as a guideline to institutionalize further and future knowledge management endeavours.

Key words: Knowledge, knowledge management, knowledge management maturity, knowledge management maturity questionnaire 


\section{Contents}

1. Introduction

2. Aim

3. Return to knowledge management maturity indicators

4. Construction of a knowledge management maturity matrix

5. Formulation of a knowledge management maturity questionnaire

6. Testing of the questionnaire for practical use

7. Findings

8. Conclusions

9. Reference

10. Appendix A

\section{Introduction}

Most knowledge management maturity models derived from the Software Engineering Institute's Capability Maturity Model unfortunately place too much emphasis on technology, neglecting or lagging behind important strategic managerial dimensions. According to Gallager and Hazlett (2004), this places major limitations on models such as KPMG's Knowledge Management Framework and Microsoft's IT Adviser for Knowledge Management. Building on the works of numerous authors (e.g. Davenport 1998, Gallager and Hazlett 2004, Pearce and Robinson 2005, Tiwana 2000, and Zack 1999), Kruger and Snyman (2005) criticize various knowledge management maturity models, arguing that progressions in knowledge management maturity (from a strategic perspective) are directly related to an increased ability to speed up the strategic cycle of imitation, consolidation and innovation. Unfortunately, in viewing knowledge management maturity from a purely strategic perspective, models and arguments proposed by authors such as those mentioned above, for the most part, remain centred on purely academic reasoning. Even though the line of reasoning proposed by these authors undoubtedly adds to the body of knowledge, very little effort is made by any of them to embark on any form of practical experimentation and/or practical adaptation of the ideas put forward. Thus, from a strategic/managerial perspective, apart from stressing the importance of technology, culture and processes in knowledge management, the literature on the subject does not help practitioners to successfully institutionalize and/or even measure knowledge management maturity. Without practical guidelines for institutionalizing and successfully measuring knowledge management maturity, more and more practitioners are starting to question the very concept of knowledge management, arguing that owing to the high cost in terms of time and commitment, and subsequent non-delivery, knowledge management is not worthy of the attention it is receiving (Kazimi, Dasgupta and Natarajan 2004).

\section{Aim}

Building on the inductive reasoning of authors such as Boon (1990), Davenport (1998), Gallagher and Hazlett (2004), Kruger and Snyman (2005), Ndlela and Du Toit (2001) and 
Zack (1999), the aim of this research was to bridge the gap between theory and practice, supplying practitioners with an instrument not only to successfully institutionalize knowledge management, but also to measure knowledge management maturity.

top

\section{Return to knowledge management maturity indicators}

Remaining true to the notion expressed by Gallager and Hazlett (2004:02) that 'there is a symbiotic relationship between the notions of measurement and evaluation and the two cannot be examined effectively in isolation', this section is devoted to revisiting the knowledge management maturity statements formulated by authors such as Boon (1990), Davenport (1998), Gallagher and Hazlett (2004), Kruger and Snyman (2005), Ndlela and Du Toit (2001) and Zack (1999). Lying hidden within the arguments proposed by these authors, especially the evaluation of maturity indicators, are questions that, once identified, can be of practical assistance in identifying the different levels of knowledge management maturity present in organizations.

In level one of their maturity model, Kruger and Snyman (2005) propose that before any formal endeavour in knowledge management commences, an organization must have a certain amount of ICT and information management (to render effective knowledge management). Using Kruger and Snyman's argument as a baseline - and in assessing the works done by authors such as Boon (1990), Gallager and Hazlett (2004) and Gurteen (1998) - it became apparent that in order to reach this preliminary level of knowledge management maturity, organizations need to comply with certain conditions, as indicated in the following questions:

- Are ICT relationships of a sound nature?

- Can the organization, arrange, make accessible, protect, store, retrieve, analyse, filter, evaluate, package and dispose of information?

- Is there an inventory of information entities in the organization?

- Can the organization organize, plan or design and evaluate an ICT system?

- Is the organization capable of shifting data and information by means of ICT, that is, is there an ICT infrastructure in place that can support information management?

- Is the organization capable of determining information needs?

- Are there measures in place to procure information?

- Can the organization determine the value and cost of information?

- Does the organization have an information policy in place?

According to arguments proposed by Davenport (1998), Logan (2001), and Taylor-Small and Tattalias (2000), the next level (level two) necessitates a realization of the importance of knowledge management as a formal function within the organization, and also an associated drive to instil this realization throughout the organization. Assessment to determine whether or not this level of maturity has been achieved, typically includes the following questions:

- Is the organization aware of the power vested in knowledge, that is, is knowledge seen as a strategic resource?

- Is there a commitment from top management to encourage a knowledge culture within the organization?

- Is there a commitment from top management to establish a formal knowledge management function?

- Is the organization capable of identifying issues, success factors and elements conducive to establishing knowledge culture and knowledge management architecture within the organization? 
- To focus all future knowledge management efforts, are there distinct expressions of the future state of knowledge (the formulation of a knowledge vision) within the organization?

Kruger and Snyman (2005) argue that the next level (level three) of maturity constitutes a conscious commitment, especially from business managers, to start embracing endeavours in knowledge management. At this level of maturity, ICT should already be geared towards supporting knowledge management endeavours. According to authors such as Davenport (1998), Laudon and Laudon (2004), Logan (2001), and Taylor-Small and Tatalias (2000), questions to determine whether or not this level of maturity has been reached, should typically include the following:

- Is ICT capable of going further than merely supporting the flow of information, to the point where it is capable of supporting management decisions and knowledge work?

- Is there an organization-wide knowledge management policy in place?

- Is knowledge shared throughout the organization, and are there forums in place to provide guidance for knowledge management activities, that is, is there a working knowledge management function, and/or knowledge domains established within the organization?

- Do functional owners send employees on formal training programmes, brainstorming sessions, self-enrichment and learning exercises?

Focusing on taking a conscious decision to formulate strategies about knowledge as a strategic resource [arguments made popular by authors such as Bater (1999), Gallagher and Hazlet (2004), Kazimi, Dasgupta and Natarajan (2004), Ndela and Du Toit (2001), Orna (1998), Seeman (1996) and Zack (1999)], the next level of maturity (level four) rests on the ability to support the assimilation and distribution of knowledge between all spheres of an organization. Questions to determine this level of maturity focus on the following conditions:

- Does the organization know what constitutes knowledge resources (both tacit and explicit), where knowledge resources are situated and why resources are strategic? In other words, is the organization capable of conducting a successful knowledge audit?

- Are there efficient and effective ICT architectures and knowledge management infrastructures in place (single access points, centralized knowledge management databases, competitive intelligence systems, single enterprise resource planning systems, integrated decision support systems, group and team supporting systems, and possibly even executive support systems)?

According to Bater (1999), Laudon and Laudon (2004), Pearce and Robinson (2005), Snyman and Kruger (2004), Von Krogh, Nonaka and Aben (2001) and Zack (1999), the next level of maturity (level five) is the ability to be able to both exploit and explore the power vested in knowledge and knowledge management. This level of maturity therefore not only depends on the ability to intentionally enhance strategy formulation, but also to streamline knowledge management processes and procedures. A checklist to determine whether or not this level of maturity has been reached, should include the following questions:

- Is the management of knowledge [all knowledge management (KM) tools] supplying a direct input to the strategic management process [is the chief knowledge officer (CKO), and the knowledge management function an active participant in the strategy formulation process of the organization]?

- Is the organization capable of formulating strategies and plans to further enhance the capabilities of knowledge management, that is, business strategies conducive to increasing knowledge in a particular area and/or leveraging existing knowledge? [According to Snyman and Kruger (2004) these plans must lead to defined knowledge 
management projects with precise expected results, due dates, priorities and responsibilities - plans to further explore, create, acquire, transfer, capture, codify, share and distribute knowledge in an effective and efficient manner.]

- Do knowledge management strategies lead to efficient and effective plans, capable of transforming the organization's knowledge structure and supporting ICT structure from the 'as is' to the required 'should be' structure?

- Does the organization have a culture conducive to knowledge sharing within its ranks?

- Are individuals being evaluated or appraised on their knowledge capabilities and output?

In referring to the works of Applegate, McFarlen and McKenny (1999), Kochikar (2004), and Pearce and Robinson (2005), Kruger and Snyman (2005) argue that as soon as organizations are capable of enhancing strategy via knowledge management, the next evolutionary step necessitates the incorporation and utilization of knowledge vested in the organization's value chain and value chain partners. This argument is similar to arguments proposed by authors such as Porter (2001) and Tapscott (2001). Porter (2001), in defending previous strategic thinking, argues that the Internet and associated technology is not causing a revolution in managerial and strategic thinking, but rather bringing about a rapid increase in the speed of doing transactions, the making of decisions and the exchange of knowledge. Although authors such as Huffman (2001), Porter (2001) and Tapscott (2001) disagree about the severity of the impact of technological innovations such as the Internet on strategy formulation, they agree that technology is becoming an enabler, a means to speed up the data-to-information-to-knowledge cycle, enabling strategists to reach the hypothetical moment of truth, the moment when all knowledge is supposed to come together, much faster. Gertler (2003), whose arguments are similar to those proposed by and Bontis, Dragonetti, Jacobson and Roos (1999) and Teece (1998), maintains that in a knowledge-rich economy in, particular, the ability to manage knowledge across borders is becoming critical to strategic management.

Kruger (2005) therefore recently argued in similar fashion that sharing knowledge across organizational boundaries, because of its social and environmental dimensions, opens up huge opportunities and also responsibilities to align and merge strategic management with knowledge management. Responding to debate surrounding the evolution of performance measurement and management, Kruger (2005) is of the opinion that a merger between strategy formulation, performance management and knowledge management has the capacity to add a dimension of geography to the knowledge-strategy cycle, opening up social interplay and enabling organizations to interact and trade knowledge (even tacit knowledge) with the very forces that shape competitiveness.

Successful value chain partnerships therefore depend on the capacity to share data and information and, according to Kruger and Snyman (2005), more specifically on the ability to share knowledge and expertise with all stakeholders in the organization's value chain. A checklist to determine whether or not this level of maturity has been reached should therefore include the following questions:

- Is knowledge shared among value chain partners (are trans-organizational forums in place)?

- Is the organization's ICT architecture capable of transcending the borders of the organization, that is, capable not only of sharing data and information, but also knowledge and expertise with all stakeholders in the organization's extended value chain?

- Have holistic knowledge management strategies been formulated among members of the value chain, for example plans and projects to further explore and exploit the power vested in knowledge? 
Kruger and Snyman (2005) are of the opinion that the final question in determining knowledge management maturity must be aimed at finding out to what extent knowledge sharing inculcates a knowledge-sharing culture within the organization. These authors also recommend that employees be allowed to propose a clairvoyant perspective of the future of knowledge management within their respective organizations. This, according to Kruger and Snyman, will provide valuable insight into the future evolutionary path needed to enhance organizational success.

\section{Construction of a knowledge management maturity matrix}

Using the above-mentioned line of reasoning, a matrix consisting of seven maturity levels was constructed. Careful scrutiny of questions contained in the KMM Matrix revealed that most, if not all, questions inadvertently test participants' perceptions of a phenomenon, in this case the progression of knowledge management maturity in an organizational setting. This means that future instruments will not only consist of a purely evaluative approach, but will also render possible the testing of phenomenological aspects.

Even though the KMM Matrix proposes numerous questions that could help practitioners to institutionalize or even determine organizational knowledge management maturity, the matrix remains encapsulated in purely theoretical propositions and may thus be 'too theoretical' and not sufficiently practical for practitioners. Achieving a balance, while at the same time being able to satisfy both evaluative and phenomenological research requirements, necessitated the benchmarking of all questions against a survey questionnaire developed by the Public Management service of the OECD (PUMA) - a questionnaire originally adapted from work done by Statistics Canada for private firms. In this regard, the OECD questionnaire was found to be of great value, mostly because experts in the fields of knowledge management and public management extensively scrutinized all the questions for significance and practical usability.

\section{Formulation of a knowledge management maturity questionnaire}

Apart from the above-mentioned benchmarking process, the proposed questionnaire was also thoroughly pre-tested and validated by a number of respected scholars in the field of knowledge management to:

- Ensure that questions are couched in unambiguous terms

- Determine if maturity progression follows a logical path and whether questions address both private and public organizational domains.

Through this validation process it became clear that the transition between phases is not cast in concrete; discrepancies and divergence between phases is a reality. It was also felt by certain scholars that some of the levels, especially Levels 3 and 4, could be combined. After numerous revisions and alterations, the final questionnaire consisted of six sections (levels), containing 101 descriptive questions (refer to Appendix A: Knowledge Management Maturity Assessment Questionnaire). It was decided that Likert-type scales (1-4) should be used to determine the extent of agreement with the personalized statements. To facilitate the capture of data, the final questionnaire was adapted for statistical use in both paper-based and electronic formats. 


\section{Testing of the questionnaire for practical use}

As argued earlier, due to the unwillingness on the part of individuals to participate, and/or unwillingness of practitioners to share information, especially information regarding strategic entities such as knowledge management maturity, most strategic and managerial research is banished to the purely theoretical and/or academic realms. Determined and cautious not to fall into this trap, the decision was taken (apart from the benchmarking process and specialists evaluating the questionnaire) to incorporate the research effort into the curriculum of MBA, M.IT and M.Com students of the University of Pretoria, South Africa. Since most (97\%) of these students are practising practitioners, thus considered 'senior' with regard to academic achievement as well as work experience, they were extremely suitable candidates to participate in the testing of the proposed questionnaire.

After numerous lectures and discussions dealing with data, information, knowledge and knowledge management, students were requested (via the use of the proposed KMMA Questionnaire) to critically evaluate the knowledge management maturity of an organization they are familiar with (preferably the organization they are working for). In addition, students were also requested to reflect on the usability and applicability of the proposed questionnaire, specifically with regard to the applicability to the environment and industry they are working in. In total 178 students (practitioners) from nine industries participated in the research effort.

At the commencement of research, the researchers thoroughly explained the anonymity of the process, purpose of the study and the importance of providing a true and honest reflection of all findings. Students were at all times allowed to voice difficulties with regard to the structure of the questionnaire as well as any form of uncertainty encountered in the proposed questions. To limit biased opinions, students were instructed to conduct interviews among strategic, middle or management as well as operational personnel in their respective organizations. After all questionnaires were returned, students were supplied with a rating system enabling them to critically evaluate and elaborate on all the findings and data gathered. Finally, to conclude the learning experience, an open session was held to elaborate on lessons learned and insight gained. Although the researchers are still in the process of scrutinizing and evaluating all data gathered by students, specifically to include all findings, deductions and conclusions in a future article, the following section supplies a short summary of conclusions reached and recommendations forwarded regarding the proposed questionnaire.

\section{Findings}

Although a number of students (less than 10\%) expressed concern about the length of the questionnaire, the majority were convinced that it served the purpose it was meant for, that is, the questionnaire covered all key aspects of knowledge management maturity. More than $80 \%$ of students agreed that the different sections in the questionnaire split the questions into logical groups, enabling respondents to focus on and complete one 'theme' before moving on to the next. Most students (approximately 70\%) felt that the use of multi-choice questions made any type of scoring easy, minimizing the possibility of misinterpretations by the assessors. A suggestion was made that space should be allowed for comments by interviewees to gain a better understanding of why they answered as they did and to assist the assessors in interpreting the answers. However, the majority of students disagreed with this recommendation, arguing that space provided for comments will make the questionnaire cumbersome and 'too long'. 
Consensus was reached among students that most respondents interviewed were not familiar with all the terminology used. It was specifically emphasized that respondents struggled to understand the distinction between knowledge management and information management. It was therefore proposed that besides the covering letter defining and explaining the difference between knowledge management and information management, a short written introduction to the questionnaire, with concrete examples of information and knowledge management, should also be included. Most students, however, felt that the structure of the questionnaire is conducive towards the conducting of structured interviews (more than $80 \%$ of students used the questionnaire exclusively as a baseline to conduct structured interviews), in which case the responsibility to establish common ground in terms of the main concepts covered in the questionnaire resides with the interviewer. Most students felt that when interviewees are allowed to complete the questionnaire on their own, discussions should take place beforehand, allowing the interviewer to define all the concepts used in all the sections covered.

Student opinion was divided, however, regarding the applicability of the questionnaire to service the needs of private, commercial companies, as well as government institutions and non-profit organizations. It was felt by a substantial number of students (approximately 35\%) that consideration must be given to the composing of a different questionnaire specifically for government institutions, non-profit organizations and also small organizations (organizations with less than 1000 employees). Arguments were aired to the effect that smaller organizations are more likely to score lower totals for certain (if not all) sections, especially section 5 of the questionnaire.

Finally, the conclusion was reached that although more extensive research needs to be conducted (especially within non-profit and small organizations), the proposed questionnaire (viewed from a holistic perspective) is very valuable in invoking the thought processes necessary to understand the concept of KM in an organizational setting. More than $80 \%$ of students therefore stated that they found the questionnaire extremely helpful, arguing that the type of questions asked are exactly what is needed to guide organizations to institutionalise and/or evaluate their knowledge management maturity. Some students even commented that the questionnaire was an eye-opener for their respective organizations, some even being tasked with undertaking further studies to rectify problems identified.

\section{Conclusion}

From this research, it is clear that the inability to bridge the gap between theoretical propositions and practical usability is not only hindering knowledge management practitioners from successfully assessing the level of knowledge management maturity reached within organizations but, more importantly, is making managers lose faith in knowledge management as a strategic enabler.

This research, more than just emphasizing the need to summarize our understanding of success factors in institutionalizing knowledge management, expressed a deliberate intention to bridge the gap between theory and practice. Unless theory culminates in usable tools, contributions made by knowledge management scholars will be of no or very little value to organizations embarking on knowledge management endeavours. Therefore, building on the inductive reasoning followed by numerous authors, and in following a process of practical experimentation, a questionnaire consisting of six (6) sections, containing 101 descriptive questions, was formulated.

Even though it is the belief of the authors that most of the essential aspects needed to 
determine knowledge management maturity are covered in the proposed questionnaire, the practical application and testing indicated that further research is urgently needed, especially on how to implement knowledge management and how to assess knowledge management maturity in non-profit and small organizations.

Knowledge management scholars are therefore invited to critically evaluate and build upon the proposed questionnaire. Unless we, as scholars, join hands and deliver practical guidelines to organizations to successfully institutionalize and measure knowledge management, all attempts to effectively harness the power vested in knowledge will be fruitless, possibly hindering an invaluable managerial resource from ever reaching its full potential.

\section{References}

Applegate, L.M., McFarlen, W.F. and McKenny, J.L. 1999. Corporate information system management: text and cases. Boston: Irwin/McGraw-Hill.

Bater, B. 1999. Knowledge management: a model approach. Managing Information 6(8):3841.

Bontis, N., Dragonetti, N.C., Jacobson, K. and Roos, G. 1999. The knowledge toolbox: a review of the tools available to measure and manage intangible resources. European Management Journa, 17(4):391-401.

Boon, J.A. 1990. Information management: an educational perspective. South African Journal of Library and Information Science 58(4):319-326.

Davenport, T.H. 1998. Some principles of knowledge management. [Online]. Available WWW: http://www.bus.utexas.edu/kman/kmprin.htm\#TOC (Accessed 12 August 2004).

Gallager, S. and Hazlett, S. 2004. Using the knowledge management maturity model as an evaluation tool. [Online]. Available WWW: http//s.gallagher@qub.ac.uk (Accessed 12 August 2004).

Gertler, M.S. 2003. Tacit knowledge and the economic geography of context, or The indefinable tacitness of being (there). Journal of Economic Geography 3(1):75-99.

Gurteen. D. 1998. Knowledge, creativity and innovation. Journal of Knowledge Management 2(1):5-13.

Huffman, B. 2001. What makes a strategy brilliant. Business Horizons 44(4):13-20.

Kazimi, J., Dasgupta, R.R. and Natarajan, G. 2004. The rise, fall and rise of knowledge management. [Online]. Available WWW: http://www zenzar.com/pdfs/km2.pdf. (Accessed 28 August 2004).

Kochikar, V.P. 2004. The knowledge management maturity model: a staggered framework for leveraging knowledge. [Online]. Available WWW:

http://www.infy.com/knowledge_capital/knowledge/KM (Accessed 12 August 2004).

Kruger C.J. 2005. Defining performance measurement - broadening the debate. Perspectives on Performance 4(3):19-20. 
Kruger, C.J. and Snyman, M.M.M. 2005. The formulation of a strategic knowledge management maturity model, South African Journal of Information Management 7(2) [Online]. Available WWW: http://www.sajim.co.za (Accessed August 2004).

Laudon, K.C. and Laudon, J. P. 2004. Management information systems. 8th ed. Upper Saddle River, New Jersey: Pearson Education.

Logan, D. 2001. Knowledge management scenario: measuring and managing intellectual assets: Gartner Symposium/ITxpo Africa, Sandton, South Africa (Unpublished).

Mark, P., Curtis, B., Chrissis, M. and Webber, S. 1993. Capability maturity model, version 1.1. IEEE Software 10(3):7-27.

Ndlela, L.T. and Du Toit, A.S.A. 2001. Establishing a knowledge management programme for competitive advantage in an enterprise. International Journal of Information Management 21(2):151-165.

Orna, E. 1998. Practical information policy. 2nd ed. Aldershot: Gower.

Pearce, J.A. and Robinson, R.B. 2005. Strategic management, formulation, implementation and control. 9th ed. Boston: McGraw-Hill.

Porter, M.E. 2001. Strategy and the Internet. Harvard Business Review 79(3): 63-78

Seeman, P. 1996. Real-world knowledge management: what's working for HoffmannLaRoche. [Online]. Available WWW: http://www.businessinnovation.ey.com (Accessed 12 August 2004).

Snyman, M.M.M and Kruger, C.J. 2004. The interdependency between strategic management and strategic knowledge management. Journal of Knowledge Management 8 (1):5-19.

Tapscott, D. 2001. Rethinking in a networked world (or why Michael Porter is wrong about the Internet), Strategy + Business 24 (Third Quarter). [Online]. Available WWW:

http://www.strategy-business.com/search (Accessed, 10 September 2005).

Taylor-Small, C. and Tattalias, J. 2000. Knowledge management model guides KM process. The Edge Newsletter, (April). [Online]. Available WWW:

http://www.mitre.org/pubs/edge/april_00.htm (Accessed 12 August 2004).

Teece, D. 1998. Capturing value from knowledge assets: the new economy, markets for know-how, and intangible assets. California Management Review 40(3):55-79.

Tiwana, A. 2000. The knowledge management toolkit: practical techniques for building a knowledge management system. Upper Saddle River: Prentice Hall.

Von Krogh, G., Nonaka, I. and Aben, M. 2001. Making the most of your company's knowledge: a strategic framework. Long Range Planning 34(1):421-439.

Zack, M.H. 1999. Developing a knowledge strategy. California Management Review 41 (3):125-145. 


\section{Appendix A}

Click here to download Appendix A: Knowledge Management Maturity Assessment Questionnaire.

\section{Disclaimer}

Articles published in SAJIM are the opinions of the authors and do not necessarily reflect the opinion of the Editor, Board, Publisher, Webmaster or the Rand Afrikaans University. The user hereby waives any claim he/she/they may have or acquire against the publisher, its suppliers, licensees and sub licensees and indemnifies all said persons from any claims, lawsuits, proceedings, costs, special, incidental, consequential or indirect damages, including damages for loss of profits, loss of business or downtime arising out of or relating to the user's use of the Website. 
ISSN 1560-683X

Published by InterWord Communications for Department of Information and Knowledge Management, University of Johannesburg 